\title{
Recent special issues of Communications in Asteroseismology
}

Apart from the regular issues CoAst also publishes special issues. The latest special issue is:

- CoAst, Vol.152 (published January 2008, ISBN 3-7001-3916-4) Conference Proceedings of the First BRITE Workshop Vienna, Austria, May 22 \& 23, 2007

Edited, Layout \& Production by Konstanze Zwintz \& Alexander Kaiser (zwintz@astro.univie.ac.at, www.brite-constellation.at)

You can access all special volumes through ADS or simply download the complete PDF file from CoAst webpage. To obtain a free paper copy, you can contact the editor of the special issue. Furthermore, most of the regular issues are also still available as paper copies. If you want to receive any of them, please contact comm.astro@univie.ac.at

\section{Upcoming special issues this year}

- Conference proceedings 'DARC/WET Workshop' Mt. Cuba, Delaware, August 1-3, 2007

- FAMIAS: The frequency analysis and mode identification software package of the FP6 Coordination Action HELAS

- Wrocław Conference proceedings 'Interpretation of Asteroseismic Data'

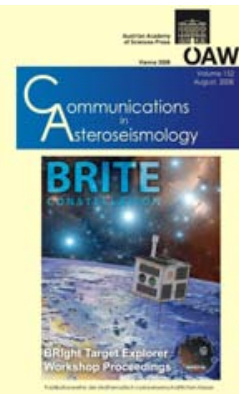

Figure 1: CoAst.152 